\title{
Metacognitive thinking and its relation to the tactical performance of fencers \\ ${ }^{*}$ Dr/ Mona Mohamed-Kamal Hijazi ${ }^{1}$ \\ ${ }^{* *}$ Dr/ Walid Ahmed Sayed Ahmed ${ }^{2}$
}

This study aimed to identify the relationship between Metacognitive thinking and tactical performance of fencing players. The researchers employed a descriptive method by using survey method in a sample of (29) fencers chosen according to the selectively intended and classified method from high standard players who participated in Egypt Cup 1 for epee public stage during the 2017/2018 season. (7) For survey, (22) for basic study. The basic sample was comprised of (12) males and (10) females, the researchers used the Arabic version of Metacognitive thinking scale presented by Jarrah and Obaidat (2011), which consists of (3) component (regulation of cognition, knowledge about cognition and knowledge processing), the most important results was that male and female fencers achieved a high level in Metacognitive thinking and its component (Regulation of cognition, Cognition processing), while they achieved a moderate level in (Knowledge about cognition), there are no statistically significant differences between male and female fencers in Metacognitive thinking and Tactical performance, the correlation coefficient is a statistically significant between the offensive tactical performance and the (Regulation of cognition, Cognition processing, the total degree of Metacognitive thinking), the Defensive tactical performance and the (Knowledge about cognition, the total degree of Metacognitive thinking), the overall degree of Tactical performance and all components of Metacognitive thinking. Key words: Metacognitive thinking, tactical performance, fencing.

\section{Introduction:}

Metacognition is one of the most recent topics of cognitive psychology. This higher-level cognition was given the label metacognition by American developmental

"Department of Combats \& Aquatics, Faculty of Physical Education, Sadat City University, Egypt

"Department of Combats \& Aquatics, Faculty of Physical Education, Sadat City University, Egypt 
psychologist (Flavell, J. H., 1976) where he noted that learners are observing for their own understanding and other cognitive activities. This means that Metacognition leads students to choose, evaluate cognitive tasks, goals and strategies that can organize their learning. They often fall into errors during the learning process as a result of their failure to do so, therefore, students should benefit from these processes in defining their goals, and strategies that can regulate their learning process.

Metacognitive thinking is a complex mental skill that is one of the most important components of intelligent behavior in information processing and grows with age and experience. It is the task of controlling all the thinking activities that work to solve the problem by using the cognitive abilities of the individual effectively in response to the requirements of thinking (Darar, A. M., 2006, 330).

Flavell defined metacognition as knowledge about cognition and control of cognition. For example, a person is engaging in metacognition if he notices that he is having more trouble learning $\mathrm{A}$ than $\mathrm{B}$, or if it strikes him that he should double-check $\mathrm{C}$ before accepting it as fact. (Flavell, $\mathbf{J}$. H. 1976, 232). This type of thinking is one of the highest levels of thinking. It requires that the individual practices the planning, monitoring and evaluation of his thinking on an ongoing basis. It is also a form of thinking that concerns the individual's observation of himself and how he uses it to think, "Think about thinking" (Atoum, A. Y., 2004, 207).

The difference between cognitive and meta-cognitive processes lies in how and where information is used, and its purpose. Where cognitive processes use tasks directly (learning experience - solving a problem ...), that is, they are used to achieve a specific goal, while meta-cognitive processes are used to plan cognitive processes, how to implement them, monitor their progress, and evaluate their results, , i.e., to ensure that the goal is achieved. Metacognitive processes are more needed when cognitive processes fail to achieve their goal, where the 
individual reviews his cognitive activities and judges how effective they are. (Roberts, M. J., Erdos, G., 1993).

The knowledge of fencer is not of value "even if he has performed all the fencing movements skillfully" unless he can apply the knowledge he learned in practical training, against different competitors, under different circumstances, and be able to analyze each new position and determines which movements and plans can be used in that situation (Ali, A. F., 2005, 191).

Play plans are the process of selecting a certain skill from a range of skills, depending on the position and condition of the player (Mowaffaq, A. M. 2011, 56) The implementation of any plan to achieve the goal required, is done only after studying the competitor well, in terms of intelligence, the ability to control the performance, the extent of response to the types of attack, and knowledge of strengths and weaknesses, and through this information, the attacker can develop an appropriate attack plan (Ali, A. F., 2005, 193).

The fencer must have the ability to think properly, and to behave in a manner that suits the situation during the duel (Nassif, A. A., Hussein, Q. H., 1988, 44), this is confirmed by (Abdul-Khaliq, E., 1999, 229) where he believes that the success factors in the implementation of play plans depend on the information and abilities of the fencer to think and act in different situations in the duel.

The player's awareness of his thinking, his ability to know his feelings, contributes to his understanding of himself, giving him the ability to manage the cognitive self, organize it, the ability to plan, and optimize the solutions to the problems and situations facing him. High performance and achievement.

If the level of the individual's metacognition skills is high, he/she can use a wide variety of ideas in new situations so that he/she can understand and solve problems.

Hence, the researchers believe that cognitive thinking may have an active role in the level tactical performance of 
fencer, since the ability of the player to analyze the performance of the opponent, and knowledge of the strengths and weaknesses of the most important factors that give the appropriate position for the fencer to acting tactically, and produces better results. On this basis, this study was to examine the relationship between the metacognitive thinking and the tactical performance level of the epee players.

\section{Aim of the study:}

This study aimed to identify the relationship between Metacognitive thinking and tactical performance for epee fencers. Hypotheses of the study:

- Are there statistically significant differences between male and female epee fencers in both metacognitive thinking and tactical performance?

- What is the relationship between thinking and metacognitive performance for epee fencers?

Materials and Methods

\section{Data collection}

\section{scale}

Metacognitive thinking

Schraw and Dennison (1994)

put it in its original form and was developed based on several theories, the regulation of cognition component was formed based on the Jacobs and Paris theory (1987), and the knowledge about cognition component was formed based on Brown's theory (1987), Jacobs and Paris theory (1987), Kumar (1998) used it on a sample of individuals and re-analyzed the scale, resulting in a third dimension,

knowledge processing. (Al-Jarrah, N., Obeidat, A., 2011) presented the Arabic version of the scale which consists of (42) paragraphs. The answer was given from five levels. Always (5) degrees, often (4) degrees, sometimes (3) degrees, rarely (2) degree, absolutely (1) degree. It measures three dimensions (regulation of cognition ranges between "19 - 95" degrees, knowledge about cognition ranges between (12 - 60) degree, and knowledge processing ranges between (11 - 55) degrees. The total score of the scale ranges between (42 - 210) degrees.

To judge the levels of Metacognition skills, grades were converted to between 1 and 5 degrees, the levels of Metacognition skills of the players were divided into categories according to the following criteria:

- From (1) to (2.33) a low
level of Metacognitive
thinking.


- $\quad$ From (2.34) to (3.67) a moderate level of Metacognitive thinking.

- $\quad$ From (3.68) to (5) a high level of Metacognitive thinking.

The Scale validity was calculated by displaying it to a group of experts (5 experts). The average of agreement among experts on the phrases was between (60\%: 100\%), the researchers were satisfied with $60 \%$ or more,

The Scale reality was calculated by the Split- half, using Alpha Cronbach equation, the correlation coefficient values between (.711, .899). Were statistically significant at $95 \%$ confidence level, which means that the scale has an acceptable degree of split- half stability using Alpha equation.

- (Offensive - Defensive) tactical Evaluation:

Using Expert evaluation (3 experts in fencing), Where the player is awarded a score of (10) for each (offensive defensive)

performance.

\section{Study method}

The

researchers

employed a descriptive method by using survey method. Which is not limited to data collection and classification, but more, because it includes an interpretation of these data. (Abdul-Hamid, J., Kazem, A.K., 2002, 134).

\section{Participants}

The study sample included (29) epee fencers, (7) for survey, (22) for basic study, (12) males, (10) females, They are chosen according to the selectively intended and classified method from high standard players who participated in Egypt Cup 1 for epee public stage, on September $28^{\text {th }}$ and September $29^{\text {th }}, 2017$ in Cairo.

\section{Research procedures:}

1 . Survey study

The researchers conducted a survey in a sample of (7) fencers from the same research community, but who were not included in the study population between September $9^{\text {th }}$ and September $15^{\text {th }}, 2017$.

2. Basic study:

The researchers conducted Metacognitive thinking scale and tactical performance Evaluation (Offensive Defensive) in the basic study sample from September $28^{\text {th }}$ to September 30 ${ }^{\text {th }}, 2017$.

\section{Results:}

Table (1) 
The significant differences between male and female fencers in Metacognitive thinking and Tactical performance

\begin{tabular}{|c|c|c|c|c|c|}
\hline & \multicolumn{2}{|c|}{ Male } & \multicolumn{2}{|c|}{ Female } & \multirow[b]{2}{*}{$\mathbf{t}$} \\
\hline & Mean & $\begin{array}{c}\text { Std. } \\
\text { Deviation }\end{array}$ & Mean & $\begin{array}{c}\text { Std. } \\
\text { Deviation }\end{array}$ & \\
\hline $\begin{array}{l}\begin{array}{l}\text { Regulation } \\
\text { cognition }\end{array} \\
\text { of }\end{array}$ & 3.763 & .1760 & 3.695 & .265 & .725 \\
\hline $\begin{array}{l}\text { Knowledge about } \\
\text { cognition }\end{array}$ & 3.396 & .352 & 3.550 & .391 & .974 \\
\hline $\begin{array}{l}\text { Cognition } \\
\text { processing }\end{array}$ & 3.955 & .270 & 3.890 & .385 & .455 \\
\hline $\begin{array}{l}\text { Metacognitive } \\
\text { thinking }\end{array}$ & 3.708 & .219 & 3.705 & .257 & .035 \\
\hline $\begin{array}{l}\text { Offensive tactical } \\
\text { performance }\end{array}$ & 7.250 & 1.138 & 7.500 & .850 & .573 \\
\hline $\begin{array}{l}\text { Defensive tactical } \\
\text { performance }\end{array}$ & 7.750 & 1.138 & 7.900 & .738 & .358 \\
\hline $\begin{array}{l}\text { Tactical } \\
\text { performance }\end{array}$ & 15.000 & 2.132 & 15.400 & 1.350 & .513 \\
\hline
\end{tabular}

T Table value for df 20 and the level of $0.05=2.086$

Table (1) shows that there are no statistically significant differences between

Table (2)

The correlation coefficient between Metacognitive thinking and Tactical performance for Fencers

\begin{tabular}{l|c|c|c|c|c}
\hline \hline & Mean & $\begin{array}{c}\text { Std. } \\
\text { Deviation }\end{array}$ & $\begin{array}{c}\text { Offensive } \\
\text { Tactical } \\
\text { performance }\end{array}$ & $\begin{array}{c}\text { Defensive } \\
\text { tactical } \\
\text { performance }\end{array}$ & $\begin{array}{c}\text { Tactical } \\
\text { performance }\end{array}$ \\
\hline \hline Regulation of cognition & 3.732 & .218 & $.501^{*}$ & .373 & $.791^{* *}$ \\
\hline Knowledge about cognition & 3.466 & .370 & .407 & $.549^{* *}$ & $.526^{*}$ \\
\hline Cognition processing & 3.926 & .321 & $.533^{*}$ & $.546^{* *}$ & $.590^{* *}$ \\
\hline Metacognitive thinking & 3.707 & .231 & $.561^{* *}$ & $.500^{*}$ & $.582^{* *}$ \\
\hline \hline
\end{tabular}

\section{Table (2) shows that: the} value of the correlation coefficient is a statistically significant between the offensive tactical performance and the (Regulation of cognition, Cognition male and female fencers in all research variables 
overall degree of Tactical performance and all components of Metacognitive thinking

\section{Discussion}

The results of table (1) showed that there are no statistically significant differences between male and female fencers in metacognitive thinking and all its components, Both male and female fencers achieved a high level in Metacognitive thinking and its component (Regulation of cognition, Cognition processing), while they achieved a moderate level in (Knowledge about cognition), where the average values ranged between $(3.396,3.955)$ for males and between (3.550, 3.890) for females. This is consistent with the findings of (Bahri, N., Fares, A., 2014). (Al-Hamouri, F., Abu-Makh, A., 2011) that there are no statistically significant differences between male and female students in metacognitive thinking and its three components.

It was also found that there were no statistically significant differences between male and female fencers in the Tactical performance level. Both male and female fencers achieved a high level of (offensive defensive) Tactical performance ranging between $(7.25,7.75)$ for males and between (7.50, 7.90) for females. While the overall score of the Tactical performance was (15.00) for males, and (15.40) for females. In this regard (Lindstroom, 1995, 30) emphasized that the learner who possesses the Metacognition skills, has the ability to direct and organize the process of learning and assume responsibility, Use thinking skills to guide and improve his thinking, Making the right decisions in different life situations, Dealing effectively with information from different sources in order to achieve a better level of understanding this information and Employment it in the situations of daily life, And to choose the appropriate procedures for the educational situation that passes through it. If the level of meta-cognitive thinking is high, students can use large and diverse repertoire of ideas in new situations, to be able to understand the subject, and to solve problems that may cause them tension, because of 
their inability to adapt, because of their inability to change the level of attention control, or inability to represent, This requires the employment of this high level of metacognitive thinking and investment in increasing the academic achievement of the students, It is also possible to take advantage of this high level in all areas of life, whether academic or social, and thus enable them to change their responses according to the situations they are exposed to (Abdul-Hafez, T. A., 2016, 387).

The results of Table (2) shows that the value of the correlation coefficient is a statistically significant between the offensive tactical performance and the (Regulation of cognition, Cognition processing, the total degree of Metacognitive thinking), the Defensive tactical performance and the (Knowledge about cognition, Cognition processing, the total degree of Metacognitive thinking), the overall degree of Tactical performance and all components of Metacognitive thinking.
Research has demonstrated the significant impact of metacognition on academic achievement and performance, Students with a higher metacognitive thinking level can adjust their knowledge and thinking to be more adaptive when solving problems, and they are considered more able to transfer their knowledge of learning strategies for new situations, They also learn and perform better than their colleagues with low metacognitive thinking. (AlJarrah, N., Obeidat, A. 2011, 146) points out that a person with a high level of metacognitive thinking performs several roles simultaneously when faced with a problem, or during an educational situation, where he plays the role of a generator of ideas, a planner, a critic, an observer of progress, a supporter of a certain idea, a guided for a particular route, and a regulator of the solution steps, Sets multiple options, evaluating each and choosing what is best, thus becoming a productive thinker.

(Al-Sherbini, F., AlTannawi, E., 2006) point out some aspects of the educational 
importance of metacognitive thinking, Such as developing the learner's ability to select, renewal, innovate, face the accelerated cognitive quantum, Enable the learner to generate creative ideas, awareness of brain processing methods, critical and creative thinking development as a result of the learner's awareness of the strategies of dealing with knowledge and ability to use them in different situations.

Technic and tactic are critical factors in success in the game, Weineck (1986) points out that the ability to win and achieve results depends on obtaining the highest level of Technical, tactical and mental abilities. Therefore, systematic planning and Technical-tactical planning should be good (Saadawi, M., 2013, 6). In practice Metacognition capacities are used to regulate one's own cognition, to maximize one's potential to think, learn and to the evaluation of proper ethical/moral rules. It can also lead to a reduction in response time for a given situation as a result of heightened awareness, and potentially reduce the time to complete problems or tasks. Metacognologists are aware of their own strengths and weaknesses, the nature of the task at hand, and available "tools" or skills. A broader repertoire of "tools" also assists in goal attainment. When "tools" are general, generic, and context independent, they are more likely to be useful in different types of learning situations.

\section{Conclusions}

Based on results of this
study, the following conclusions can be drawn:

1- Male and female epee fencers achieved a high level in Metacognitive thinking, and tactical performance (offensive - defensive).

2- There are no differences between male and female fencers in Metacognitive thinking and Tactical performance.

3- There is a positive correlation between the components of Metacognitive thinking and the tactical performance of fencing players.

\section{Recommendations}

Based on the aim of the study and the collected data, the following implications can be made:

1. It is necessary to use educational and training methods focused on developing 
the Metacognitive thinking skills for fencers.

2. Conducting more scientific research dealing with the relationship between Metacognitive thinking and other mental processes in various sports activities.

\section{References:}

1- Abdul-Hafez, T. A.: Metacognitive thinking and its Relation to Knowledge Flexibility among University Students, Journal of Alostaz, 2016; 217, Volume II

2- Abdul-Hamid, J., Kazem, A. K.: Research Methods in Education and Psychology, Cairo: Dar Al-Nahda AlArabia for Publishing and Distribution; 2002

3- Abdul-Khaliq, E.: Sports Training, Theories, Applications, Alexandria: I 9, Dar Al Ma'aref; 1999

4- Al-Atoum, A. Y: Cognitive Psychology between Theory and Practice, Amman: Dar AlMasirah Publishing and Distribution; 2004

5- Al-Hamouri, F., AbuMakh, A: The Level of Need for Knowledge and metacognitive thinking among
Undergraduate Students at Yarmouk University, An-Najah University Journal of Humanities, 2011; 25 (6)

6- Ali, A. F: Tactical knowledge and its relation to the tactical behavior in foil, Journal of the Faculty of Physical Education Baghdad University, 2005; 14 (2)

7- Al-Jarrah, N., Obeidat, A: The Level of Transcendental Thinking among a Sample of Yarmouk University Students in Light of Some Variables, Jordanian Journal of Educational Sciences, 2011; 7 (2): 145-162

8- Al-Sherbini, F., AlTannawi, E." Metacognition Strategies between Theory and Practice, Mansoura: Modern Library of Publishing and Distribution; 2006

9- Bahri, N., Fares, A: Metacognition and its and its relationship with Problem Solving in Third Year Secondary School Students, Journal of Human Sciences, Algeria, 2014; A (41)

10- Darar, A. M: Education and Development of Thinking, The Regional Scientific 


\section{6}

Conference of Talent on the Care of Talent Education for the Future, King Abdul Aziz Foundation and His Men for Giftedness, Saudi Arabia, 2006 11- Flavell, J. H. (1976). Metacognitive aspects of problem solving. In L. B. Resnick (Ed.), the nature of intelligence, 1976; (pp. 231235). Hillsdale, NJ: Lawrence Erlbaum Associates.

12- Lindstrom, C: Enpower The Child with learning Difficulties to Think Metacognitively, Australian Journal of Remedial, Education, 1995; 27 (2):28-31
13- Mowaffaq, A. M. Learning and Basic Skills in Football, Amman: Dar Dijla; 2011

14- Nassif, A. A., Hussein, Q.

H. Principles of Sports Training, Baghdad: Higher Education Press; 1988

15- Roberts, M. J., Erdos, G. Strategy selection and metacognition. Educational Psychology, 1993; 13(3-4): 259-266

16- Saadawi, M: Analytical study of the Technical and tactical performance of the Algerian youth team and the African teams, $\mathrm{PhD}$ thesis, 2013; University of Algiers. 